\title{
ANALYSIS OF URBAN FOREST CARBON SEQUESTRATION CAPACITY: A CASE STUDY OF ZENGDU, SUIZHOU
}

\author{
Xiaomin Yu, Haitao Wang*, Wei Cai, Yifei Han \\ Hubei Geomatics Information Center (Hubei Research Institute of Beidou Satellite Navigation Applied \\ Technology), Minzu Avenue 39, Wuhan, Hubei, China, 430074 - (37952574, 306550757, 56311244, 525780746) @qq.com
}

\author{
Commission IV, WG IV/3
}

KEY WORDS: Carbon Sequestration, CITYGREEN Model, Urban Forest Ecosystem, National Geographic Census, Zengdu

\begin{abstract}
:
Carbon-fixing and oxygen-releasing is an important content of forest ecosystem serving in city. Analysis of forest ecosystem carbon sequestration capacity can provide scientific reference for urban forest management strategies. Taking Zengdu of Suizhou as an example, CITYGREEN model was applied to calculate the carbon sequestration benefits of urban forest ecosystem in this paper. And the carbon sequestration potential of urban forest ecosystem following the returning of farmland to forest land is also evaluated. The results show that forest area, percent tree cover, and the structure of forest land were the major factors reflecting regional carbon sequestration capacity.
\end{abstract}

\section{INTRODUCTION}

Analysis of urban forest carbon sequestration capacity can improve people's cognitive level for forest ecological functions and values, and help decision-makers at all levels to recognize the value of urban green infrastructure. It can also provide scientific basis for tackling regional climate change, forest management, mid-to long term development planning and development of forest carbon sink market, so as to build a healthy ecological urban environment.

Urban forest carbon sequestration capacity can be evaluated by a series of indicators, such as carbon storage, carbon sequestration, etc. Carbon storage is the total amount of carbon held in a tree's wood (biomass). Carbon sequestration is the rate at which trees store carbon. We can scientifically evaluate a city's carbon balance and provide scientific reference for devising urban forest management policies, and quantitatively analysing forest carbon sequestration capacity by counting the indicators of carbon storage, carbon sequestration, etc.

Before the 1990s, people paid little attention to urban forest carbon storage research. And the study on urban forest carbon storage was predominantly found in the United States, Europe and other developed countries, adopting traditional relative growth model and CITYGREEN model combined with remote sensing technology as the research methods. Domestic studies on urban forest carbon storage start relatively late. Taking the foreign research methods that based on existing urban forest census data and temporarily plot survey data as reference, most of them use biomass equations, remote sensing, and CITYGREEN model to study the carbon sequestration potential of urban forest.

\section{CTIYGREEN MODEL}

CITYGREEN's carbon module quantifies the role of urban forests in removing atmospheric carbon dioxide and storing carbon. Based on trunk diameter, CITYGREEN estimates the age distribution of trees within a given site and assigns one of three Age Distribution Types. Type I represents a distribution of comparatively young trees. Type 2 represents a distribution of older trees. Type 3 describes a site with a balanced distribution of age. Sites with older trees (with more biomass) are assumed to store more carbon than those with younger trees (less biomass) and other species. Each distribution type is associated with a multiplier, which is combined with the overall size of the site and the site's canopy coverage to estimate how much carbon is removed on a given site. The program estimates annual sequestration, or the rate at which carbon is removed, and the current storage in existing trees. Both are reported in tons.

In CITYGREEN model, carbon storage and carbon sequestration estimation are highly dependent on the multipliers, which are further assigned to three predominant tree diameter distribution types shown in table 1.

\begin{tabular}{|c|c|c|}
\hline Distribution Type & $\begin{array}{c}\text { Carbone Storage } \\
\text { Multipliers }\end{array}$ & $\begin{array}{c}\text { Carbon } \\
\text { Sequestration } \\
\text { Multipliers }\end{array}$ \\
\hline $\begin{array}{c}\text { Type 1(Young } \\
\text { population) }\end{array}$ & 0.3226 & 0.00727 \\
\hline $\begin{array}{c}\text { Type 2(Moderate } \\
\text { Plantings) }\end{array}$ & 0.4423 & 0.00077 \\
\hline $\begin{array}{c}\text { Type 3(Even } \\
\text { Distribution) }\end{array}$ & 0.5393 & 0.00153 \\
\hline $\begin{array}{c}\text { Type 4(Average } \\
\text { Distribution) }\end{array}$ & 0.4303 & 0.00335 \\
\hline
\end{tabular}

Table 1. Multipliers in CITYGREEN model

CITYGREEN uses these multipliers to estimate carbon storage capacity and carbon sequestration rates. To estimate carbon storage in a study area:

* Corresponding author 


$$
C_{t}=A \times F \times N_{t}
$$

To estimate carbon sequestration annual rate:

$$
C_{r}=A \times F \times N_{r}
$$

In the formula, $C_{t}$ and $C_{r}$ respectively represent carbon storage (tons) and carbon sequestration annual rate (tons/year), $A$ represents regional area (acres), $F$ represents tree cover percentage, $N_{t}$ and $N_{r}$ respectively represent carbon storage Multipliers and carbon sequestration Multipliers.

\section{RESULTS}

\subsection{Carbon sequestration status}

The forest classification data of the first national geographic census results in Zengdu is used in this paper as the input data of CITYGREEN model. Assuming that sparse shrub, artificial young plantation, and sparse forest are type 1 , high forest, shrub wood, shrub and mixed forest, and bamboo are type 2, greenland is type 3, under the CITYGREEN model, carbon storage and carbon sequestration annual rate of Zengdu and its towns are shown in Table 2. And Carbon sequestration status about each town of Zengdu is qualitatively demonstrated in Figure 1 and Figure 2.

\begin{tabular}{|c|c|c|c|c|}
\hline NO. & $\begin{array}{c}\text { Administrative } \\
\text { Division }\end{array}$ & Forest Area $\left(\mathrm{KM}^{2}\right)$ & Carbon Storage (ton) & $\begin{array}{c}\text { Carbon Sequestration } \\
\text { Annual Rate }\end{array}$ \\
\hline 1 & Xicheng Street & 0.05 & 7.15 & 0.02 \\
\hline 2 & $\begin{array}{c}\text { Dongcheng } \\
\text { Street }\end{array}$ & 9.28 & 975.83 & 4.05 \\
\hline 3 & Nanjiao Street & 37.10 & 3958.68 & 12.54 \\
\hline 4 & Beijiao Street & 16.01 & 1621.57 & 47.45 \\
\hline 5 & Wandian Town & 94.58 & 9794.88 & 39.54 \\
\hline 6 & Hedian Town & 117.88 & 12570.89 & 35.84 \\
\hline 7 & LuoyangTown & 155.66 & 16898.26 & 40.41 \\
\hline 8 & Fuhe Town & 87.56 & 9287.72 & 221.94 \\
\hline 9 & Xihe Town & 82.20 & 8527.64 & 63642.62 \\
\hline \multicolumn{2}{|l|}{ Total of Zengdu District } & 600.33 & & \\
\hline
\end{tabular}

Table 2. Carbon sequestration status of Zengdu and its towns

As we can see from Table 2, carbon storage is proportional to the regional forest area. The larger the woodland area, the higher the carbon storage. Regional carbon sequestration annual rate is not only closely related to the forest area, but also the composition and types of forest land. For example, Luoyang town's forest area and carbon storage is larger and higher than Wandian and Hedian town, but its carbon sequestration is lower than Wandian and Hedian town. The reason lies in that Wandian and Hedian town have certain advantages in terms of forest land composition and types.

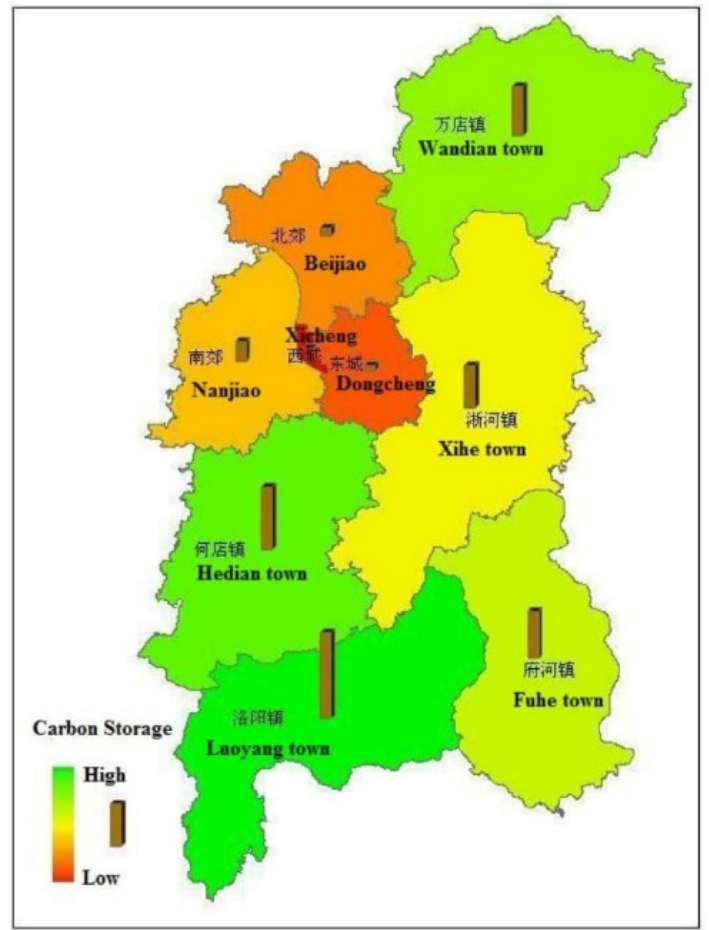

Figure 1. Carbon storage of Zengdu and its towns 


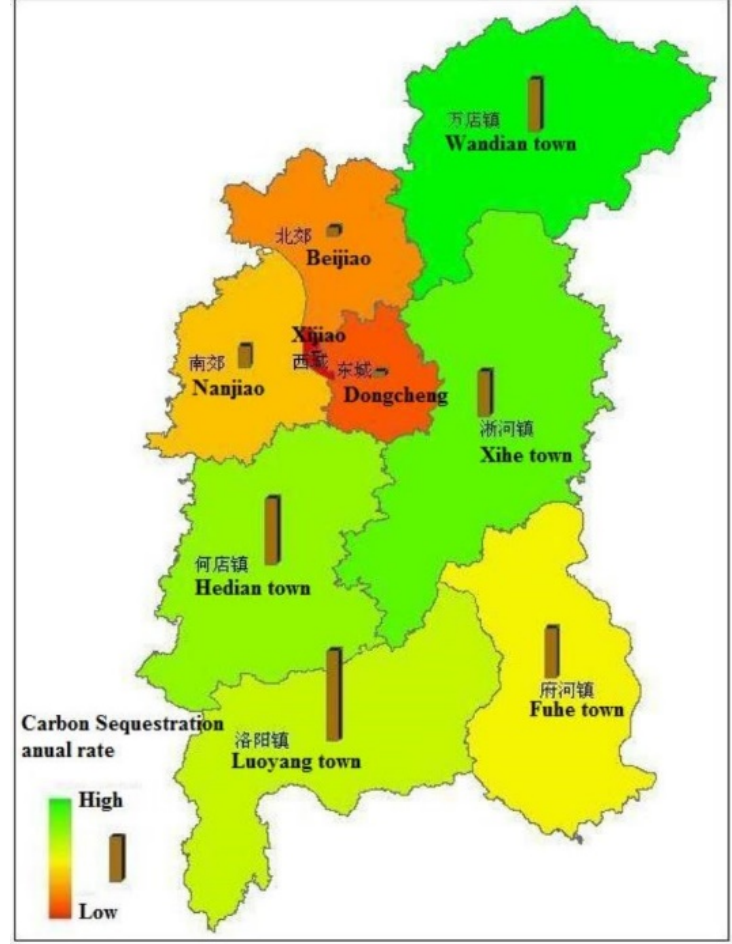

Figure 2. Carbon sequestration annual rates of Zengdu and its towns

\subsection{Carbon sequestration potential}

According to Chinese policy of returning farmland to forest land, farmlands (including terrace) with slope more than 25 degrees should be transformed to ecological forest land so as to effectively improve the regional carbon sequestration capacity. Based on the national policy, the newly added forest land area of Zengdu and its towns could be calculated using land cover classification data and slope data of the first national geographic census results in Zengdu. Assuming the forest which returned from farmland presenting average distribution, the carbon sequestration potential of Zengdu and its towns can be obtained through CITYGREEN model, as shown in table 3.

\begin{tabular}{|c|c|c|c|c|}
\hline NO. & $\begin{array}{l}\text { Administrative } \\
\text { Division }\end{array}$ & $\begin{array}{c}\text { Forest } \\
\text { Area } \\
\left(\mathrm{KM}^{2}\right)\end{array}$ & $\begin{array}{c}\text { Carbon } \\
\text { Storage } \\
\text { (ton) }\end{array}$ & $\begin{array}{c}\text { Carbon } \\
\text { Sequestration } \\
\text { Annual Rate }\end{array}$ \\
\hline 1 & Xicheng Street & 0 & 0 & 0 \\
\hline 2 & $\begin{array}{l}\text { Dongcheng } \\
\text { Street }\end{array}$ & 0.05 & 5.11 & 0.04 \\
\hline 3 & Nanjiao Street & 0.08 & 8.70 & 0.07 \\
\hline 4 & Beijiao Street & 0.01 & 0.87 & 0.01 \\
\hline 5 & Wandian Town & 0.14 & 15.20 & 0.12 \\
\hline 6 & Hedian Town & 0.60 & 63.43 & 0.49 \\
\hline 7 & LuoyangTown & 0.91 & 97.29 & 0.76 \\
\hline 8 & Fuhe Town & 0.18 & 19.57 & 0.15 \\
\hline 9 & Xihe Town & 0.19 & 20.30 & 0.16 \\
\hline \multicolumn{2}{|c|}{ Total of Zengdu } & 2.17 & 230.47 & 1.79 \\
\hline
\end{tabular}

Table 3. Carbon sequestration potential of Zengdu and its towns

From table 3, we can see that regional carbon sequestration potential of the forest returned from farmland is proportional to the newly added forest land area. After returning farmland to forest, the carbon storage of Zengdu will increase about 230.47 tons $0.36 \%$ of total carbon storage. And carbon sequestration annual rate will increase 1.79 tons/year with growth rate of $0.81 \%$. Carbon sequestration protential about each town of Zengdu after returning farmland to forest is qualitatively showedn in Figure 3 and Figure4.

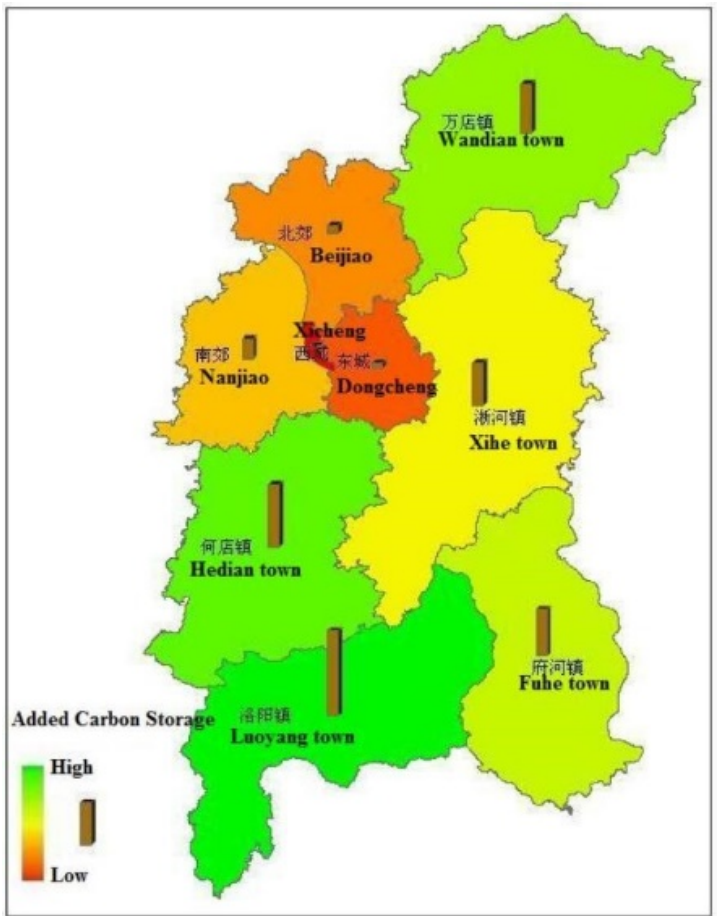

Figure 3. Carbon storage after returning farmland to forest about each town of Zengdu

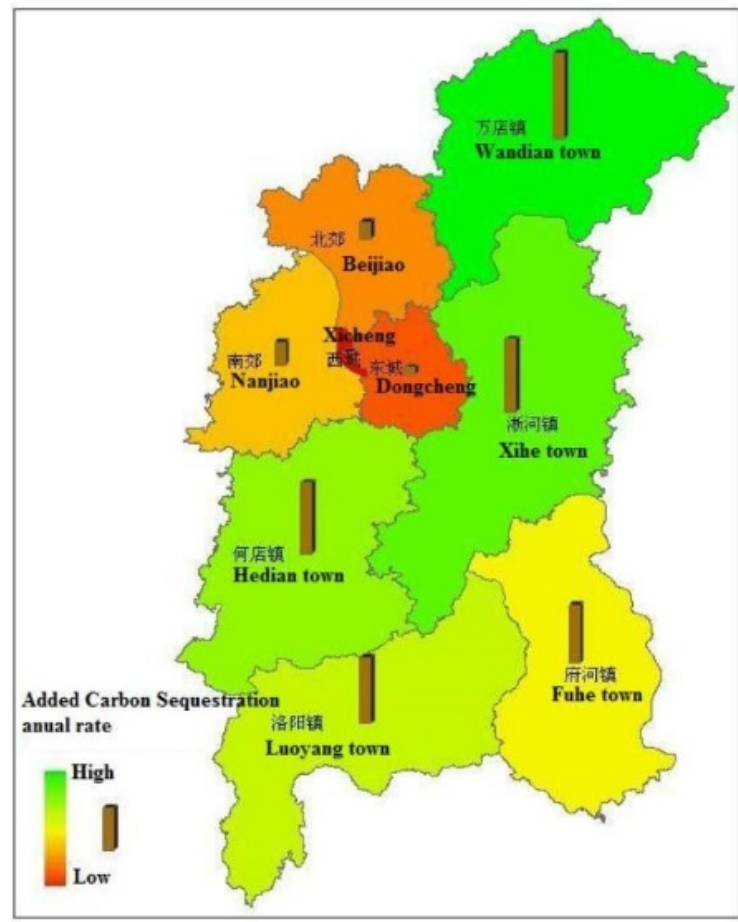

Figure 4. Carbon sequestration annual rates after returning farmland to forest about each town of Zengdu 


\section{CONCLUDING REMARKS}

By analyzing the above results, it can be found that forest area and tree cover percentage are the major factors reflecting regional carbon sequestration capacity. Usually, the larger the area and the higher the tree cover percentage, and the carbon sequestration capacity will also be stronger. In addition, the structure of forest land (a combination of trees at different age) is also an important factor influencing forest carbon sequestration. Therefore, in order to promote the forest carbon sequestration capacity and improve the regional ecological environment, we need to select the forest types with carbon sequestration advantage, and make good planning and management of forest land when enlarging the forest area and increasing the tree cover percentage. Last but not least strictly following the national policy of returning farmland to forest can also effectively help us improve the regional carbon sequestration capacity.

\section{ACKNOWLEDGEMENTS}

The paper is Funded By Open Research Fund Program of Key Laboratory for National Geographic Census and Monitoring, National Administration of Surveying, Mapping and Geoinformation, NGCM (2015NGCM10).

\section{REFERENCES}

American Forests, 2002. CITYgreen 5.0 User Manual [M].Washington D.C.: American Forests.

D.S. Wang, M.S. Kuang, X.J. Zhang, etc. 2012, A Remote Sensing-Based Research about the Evolution of City Greenbelts and Their Carbon Sequestration Ability-A Case Study in Chongqing Main City Zone. Journal of Southwest China Normal University (Natural Science Edition), 37(3):105-112.

L. Chen, P.W. Li, G.C. Li, etc. 2009, Application of CITYGREEN model in air purification, carbon fixation and oxygen release by greenbelt system of Shenzhen City. ACTA ECOLOGICA SINICA, 29(1):272-282.

L.H. Peng, S. Chen, Y.X. Liu, etc. 2007, Application of Citygreen model in benefit assessment of Nanjing urban greenbelt in carbon fixation and runoff reduction. Chinese Journal of Applied Ecology, 18(6):1293-1298.

L.P. Zhang, Y.B. Wu, Z.H. Zheng, etc. 2012, Ecological benefits evaluation of forests in Suzhou city based on CITYgreen model. Journal of Nanjing Forestry University (Natural Science Edition), 36(1):59-62

X.M. Yu, B. Li, Z.Q. Duan, etc. 2015, Study on Carbon Sequestration Ability Evolution of Shenzhen Urban Greenbelt. Geospatial Information, Vol.13, No.4, pp. 140-142.

W. Li. 2007, The Application Of CITYgreen in Urban greenland ecological benefits evaluation. Mater degree thesis of Beijing Forestry University. 